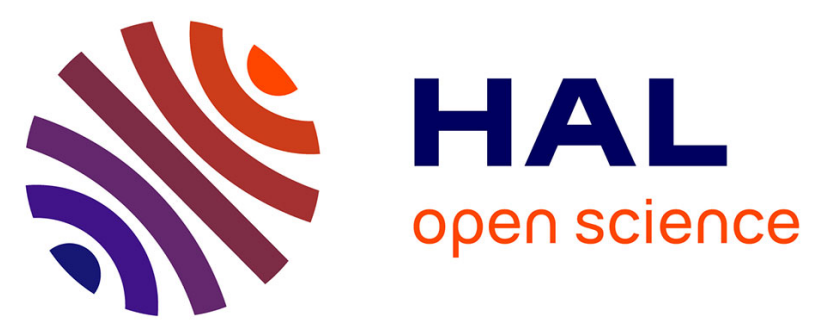

\title{
Hydrogen/Deuterium Exchange Mass Spectrometry for the Structural Analysis of Detergent-Solubilized Membrane Proteins
}

\author{
Darragh O’brien, Véronique Hourdel, Alexandre Chenal, Sébastien Brier
}

\section{To cite this version:}

Darragh O'brien, Véronique Hourdel, Alexandre Chenal, Sébastien Brier. Hydrogen/Deuterium Exchange Mass Spectrometry for the Structural Analysis of Detergent-Solubilized Membrane Proteins. Springer. Expression, Purification, and Structural Biology of Membrane Proteins, 2127, Humana, New York, NY, pp.339-358, 2020, Methods in Molecular Biology, 978-1-0716-0372-7. 10.1007/978-10716-0373-4_22. pasteur-02559306

\section{HAL Id: pasteur-02559306}

https://hal-pasteur.archives-ouvertes.fr/pasteur-02559306

Submitted on 31 Jul 2020

HAL is a multi-disciplinary open access archive for the deposit and dissemination of scientific research documents, whether they are published or not. The documents may come from teaching and research institutions in France or abroad, or from public or private research centers.
L'archive ouverte pluridisciplinaire HAL, est destinée au dépôt et à la diffusion de documents scientifiques de niveau recherche, publiés ou non, émanant des établissements d'enseignement et de recherche français ou étrangers, des laboratoires publics ou privés. 


\title{
Hydrogen/Deuterium Exchange Mass Spectrometry for the structural analysis of detergent-solubilized membrane proteins
}

\author{
Darragh P.O’Brien ${ }^{1, \#}$, Véronique Hourdel ${ }^{2}$, Alexandre Chenal ${ }^{1}$ and Sébastien Brier ${ }^{3}$
}

\footnotetext{
${ }^{1}$ Biochemistry of Macromolecular Interaction Unit, Department of Structural Biology and Chemistry, Institut Pasteur; CNRS UMR3528; Paris, France.

${ }^{2}$ Environment and Infectious Risks Unit, Department of Infection and Epidemiology, Institut Pasteur; Paris, France.

${ }^{3}$ Biological NMR Technological Platform, Center for Technological Resources and Research, Department of Structural Biology and Chemistry, Institut Pasteur; CNRS UMR3528; Paris, France. \#Current Address: Target Discovery Institute, Nuffield Department of Medicine, University of Oxford, Oxford OX3 7FZ, United Kingdom.
}

Running title: HDX-MS of detergent-solubilized membrane proteins 


\section{i. Abstract}

Integral membrane proteins are involved in numerous biological functions and represent important drug targets. Despite their abundance in the human proteome, the number of of integral membrane protein structures is largely underrepresented in the Protein Data Bank. The challenges associated with the biophysical characterization of such biological systems is well known. Most structural approaches, including X-Ray crystallography, SAXS, or mass spectrometry (MS), require the complete solubilization of membrane proteins in aqueous solutions. Detergents are frequently used for this task, but may interfere with the analysis, as is the case with MS. The use of "MS-friendly" detergents, such as non-ionic alkyl glycoside detergents, has greatly facilitated the analaysis of detergent-solubilized membrane proteins. Here, we describe a protocol which we have successfully implemented in our laboratory to study the struture and dynamics of detergent-solubilized integral membrane proteins by Hydrogen/Deuterium eXchange and Mass Spectometry (HDX-MS). The procedure does not require detergent removal prior to MS analysis, instead taking advantage of the ultra-high pressure chromatographic system to separate deuterated peptides from "MS-friendly" detergents.

\section{ii. Key words}

Integral membrane proteins, "MS-friendly" detergents, ligand binding, deuterium exchange, mass spectrometry 


\section{Introduction}

Hydrogen/Deuterium eXchange measured by Mass Spectrometry (HDX-MS) is a well-established and robust method to study the structure and dynamics of proteins [1-5]. The rate of exchange between backbone amide hydrogens and deuterium is directly influenced by the structure and dynamics of proteins. Disordered regions that lack stable hydrogen bonding networks exchange very rapidly whereas folded elements, such as $\alpha$-helices and $\beta$-sheets, exchange at much slower rates due to hydrogen bonding [6]. Over the last 35 years, HDX-MS has been extensively used (mainly in the academic sector) to study the structure, folding and dynamics of soluble proteins and to characterize their interactions with partners (e.g., DNA, peptides, membranes, lipids, small molecules etc. [7-11]). The structural information gathered by HDX-MS has proved to be extremely valuable and complementary to X-ray crystallography [12-14], SAXS [15,16], NMR spectroscopy [17], or other classical structural tools [18], underlining the utility of this technology in structural biology studies. HDX-MS has long been perceived as a powerful, but complex and time-consuming structural technique. The analysis of deuterated samples by MS necessitates quenching of the labeling reaction prior to monitoring the deuterium uptake by simultaneously adjusting the $\mathrm{pH}$ and the temperature to 2.5 and $0^{\circ} \mathrm{C}$, respectively. This step is critical to minimize as much deuterium loss as possible (i.e., back-exchange) during the chromatographic and MS steps. Under these so-called "quench conditions", the exchange rate constant of backbone amide hydrogens is greatly reduced (i.e., by approximatively five orders of magnitude compared to exchange at $\mathrm{pH} 7.0$ and $25^{\circ} \mathrm{C}$ ) which provides "enough" time to perform LC-MS acquisition. However, such quench conditions must be maintained throughout the analysis, including during the digestion and chromatographic steps. This technical challenge has greatly hindered the expansion of HDX-MS, limiting its use to MS-specialized laboratories only. Over the past decade however, significant improvements in the HDX-MS workflow have resulted in the technology becoming more streamlined and robust, enhancing its accessibility in both academic and pharmaceutical environments. In particular, the development of dedicated robots for automated sample handling, the commercialization of refrigerated ultra-high performance liquid 
chromatography systems [19] and the automation of the rather labor-intensive data processing step have greatly simplified HDX-MS strategies [20-23].

Consequently, the use of modern HDX-MS workflows finally enables the structural analysis of more complex biological systems, such as entire viral particles [24] and membrane proteins [25-30]. One challenge still associated with this latter, however, remains their production and purification from their native environment, whilst maintaining a fully functional state. For this task, detergents have been traditionally used to extract and purify membrane proteins from biological membranes.

Unfortunately, MS does not tolerate most detergents, due to their high ionization propensity, leading to ion signal suppression of peptides and proteins. Specific procedures for detergent removal have been developed, such as affinity-based spin columns [31], or filter-aided sample preparation [32]. Although these clean-up strategies work well, they are not compatible with the time constraints and/or the quench conditions imposed by the HDX-MS technology.

In this chapter, we report a HDX-MS protocol for the structural analysis of integral membrane proteins solubilized in 'MS-friendly' detergent micelles. This protocol was initially developed in our laboratory to decipher the solvent accessibility and dynamics of the human glutamate transporter (EAAT1) solubilized in dodecanoyl sucrose micelles [12,33]. Importantly, the procedure described below does not require any sample clean-up prior to MS analysis, and makes use of the refrigerated ultra-high performance liquid chromatography system to separate deuterated peptides from "MSfriendly" detergents, thus avoiding ion signal suppression.

\section{Materials}

\subsection{Reagents}

1. Deuterium oxide $\left(\mathrm{D}_{2} \mathrm{O}\right), 99.9$ atom \% D, $25 \mathrm{~g}$ (Sigma Aldrich).

2. Deuterium chloride solution (DCl), 35 wt. in $\mathrm{D}_{2} 0,99$ atom \%D (Sigma Aldrich).

3. Sodium deuteroxide solution (NaOD), 40 wt. in $\mathrm{D}_{2} 0,99$ atom \% (Sigma Aldrich).

4. Immobilized agarose pepsin beads (50\% slurry, Thermo Scientific).

5. Acetonitrile (LC-MS grade). 
6. Formic acid (LC-MS grade).

7. Highly pure detergents (Anagrade; Anatrace).

8. Ultrapure water (either from a MilliQ system or UPLC grade).

Note: \% refers to volume: volume (v:v), unless specified.

\subsection{Buffers}

The following buffers were used to study the uptake behavior of the human EAAT1 protein solubilized in DoDecanoyl Sucrose (DDS, CMC in $\mathrm{H}_{2} \mathrm{O} \sim 0.016 \%$ (w:v)) in the presence and absence of the selective non-substrate EAAT1 inhibitor UCPH-101 [12]. The labeling and dilution buffers should both be identical to the initial protein buffer.

1. Dilution buffer: $50 \mathrm{mM}$ HEPES, $200 \mathrm{mM} \mathrm{NaCl}, 1 \mathrm{mM}$ L-Aspartate, 5\% glycerol, $0.0632 \%$ (w:v) DDS ( 3 x CMC), 0.01264\% (w:v) Cholesteryl HemiSuccinate (CHS), 0.5 mM TCEP, 2.2\% DMSO, pH 7.4 (in $\mathrm{H}_{2} 0$ ).

2. Labeling buffer: $50 \mathrm{mM}$ HEPES, $200 \mathrm{mM} \mathrm{NaCl}, 1 \mathrm{mM}$ L-Aspartate, $5 \%$ glycerol, $0.0632 \%$ (w:v) DDS, 0.01264\% (w:v) CHS, 0.5 mM TCEP supplemented with either DMSO or 101.2 $\mu \mathrm{M}$ UCPH-101 prepared in 100\% DMSO, pD 7.4 in $\mathrm{D}_{2} 0$ (Final DMSO concentration $\left.=2.2 \%\right)$ (See Note 1).

3. Quench buffer: ice-cold solution of $0.75 \%$ formic acid supplemented with $5 \%$ glycerol.

\subsection{LC-MS materials and solutions}

1. Empty $2 \mathrm{~mm}$ I.D. $\mathrm{x} 2 \mathrm{~cm}$ long guard column (model C-130B, Upchurch Scientific) with $2 \mu \mathrm{m}$ frits.

2. ACQUITY UPLC BEH C18 VanGuard Pre-Column, $130 \AA ̊$, $1.7 \mu \mathrm{m}, 2.1 \mathrm{~mm}$ x 5 mm (Waters Corporation).

3. ACQUITY UPLC BEH C18 Analytical column, $130 \AA ̊$, $1.7 \mu \mathrm{m}, 1.0 \mathrm{~mm}$ x 100 mm (Waters Corporation).

4. Pepsin wash solution: $1 \%$ formic acid, $5 \%$ acetonitrile, $1.5 \mathrm{M}$ guanidinium chloride, $\mathrm{pH}$ 1.7. 
5. Lockmass solution: [Glu1]-Fibrinopeptide B human (Sigma Aldrich) prepared at $100 \mathrm{nM}$ in $50 \%$ acetonitrile, $0.1 \%$ formic acid.

\subsection{Software}

1. ProteinLynX Global Server 3.0 (PLGS; Waters Corporation).

2. DynamX 3.0 (Waters Corporation).

3. MEMHDX (http://memhdx.c3bi.pasteur.fr) [20].

\section{Methods}

The structural analysis of membrane proteins solubilized in "MS-friendly" detergents does not require changes to the classical HDX-MS workflow (Fig. 1). Before initiating the labeling, the protein is equilibrated at the desired temperature (depending on the stability of the biological system), in the presence or absence of a ligand (small molecules, proteins, peptides, etc.). The labeling starts by diluting the equilibrated sample with a large excess of deuterated buffer. The excess of deuterium favors the unidirectional exchange of labile backbone amide hydrogens (from $\mathrm{H}$ to $\mathrm{D}$ ). The protein sample is left to incubate at the desired temperature; after defined periods of time, aliquots are removed and quenched by reducing the $\mathrm{pH}$ to 2.5 , and the temperature to $0^{\circ} \mathrm{C}$. Quenched samples can be snap-frozen and stored at $-80^{\circ} \mathrm{C}$ or immediately digested by an acidic protease under quench conditions. The generated peptides are further separated on a C18 reverse phase column maintained at $0^{\circ} \mathrm{C}$ and directly eluted onto the mass spectrometer.

[Figure 1 near here]

The term "MS-friendly" detergents mainly refers to non-ionic alkyl glycoside detergents [R-O$\left(\mathrm{CH}_{2}\right)_{\mathrm{n}}-\mathrm{CH}_{3}$ with $\mathrm{R}=$ Glucose; or R-S- $\left(\mathrm{CH}_{2}\right)_{\mathrm{n}}-\mathrm{CH}_{3}$ with $\mathrm{R}=$ glucose, maltose: $e$.g., $\mathrm{n}$-Dodecyl- $\beta-\mathrm{D}-$ maltopyranoside (DDM), or sucrose monododecanoate] or zwitterionic detergents such as $n$ Tetradecyl-N,N-dimethyl-3-ammonio-1-propanesulfonate (Zwittergent 3-14). However, "MSfriendly" is not equivalent to "MS-compatible" (See Note 2). Hence, the co-elution of "MS-friendly" detergents with proteins or peptides during electrospray ionization-MS analysis ultimately results in 
an almost complete loss of protein / peptide signal. One simple solution to overcome this is to use the chromatographic system to separate the deuterated peptides obtained after digestion from the detergent, based on their inherent differences in hydrophobicity. The HDX-MS protocol described in this chapter is based on the above-mentioned strategy, and was applied to investigate the changes of solvent accessibility occurring on a thermostabilized form of EEAT1, in the presence and absence of UCPH-101.

\subsection{From sample preparation to data acquisition}

\subsubsection{Preparation of the "home-made" pepsin column}

1. Assemble the analytical guard column following the vendor's instructions. Unscrew one side of the column, remove the frit, and attach the packing funnel. Connect a 1/16 inch syringe PEEK connector at the other extremity and attach an empty $10 \mathrm{~mL}$ syringe.

2. Mix the $50 \%$ pepsin slurry and load $\sim 150 \mu \mathrm{L}$ (i.e., $\sim 75 \mu \mathrm{L}$ of settled agarose beads) onto the packing funnel. Use the syringe to create a small and constant aspiration to pour the slurry. The $2 \mathrm{~mm}$ I.D. $\mathrm{x} 2 \mathrm{~cm} \mathrm{C}-130 \mathrm{~B}$ guard column can accommodate up to $\sim 63 \mu \mathrm{L}$ of pepsin beads (See Note 3).

3. Once the guard column is completely filled, remove the syringe and the packing funnel and place the frit onto the open end. Screw the column cap.

4. Connect the pepsin column to the UPLC system and flush with 10 to 20 column volume of $0.15 \%$ formic acid buffer, $\mathrm{pH} 2.5$, at $40 \mu \mathrm{L} / \mathrm{min}$ and room temperature. At the end of the cleaning procedure, increase the flow rate to $100 \mu \mathrm{L} / \mathrm{min}$ for several minutes to finish packing the column.

5. Control the activity of the pepsin column by injecting a reference protein sample (See Note 4).

6. Close both ends of the column with a plug to avoid drying and place at $4{ }^{\circ} \mathrm{C}$ until use. When stored and used properly, the pepsin column lasts the entire life of a project (and more). 


\subsubsection{Optimizing the digestion and LC conditions}

The first step of any HDX-MS project is to define and optimize the digestion and LC conditions. The generation of a good peptide map (i.e., high sequence coverage, redundancy, signal quality etc.) is essential and represents the most important criterion to evaluate the feasibility of a project [34]. The digestion can take place either online (using columns of immobilized acidic proteases) or offline (i.e., in solution) using solubilized or immobilized acidic proteases (See Note 5). The following steps describe the conditions employed to generate a peptide map of the DDS-solubilized EAAT1 protein with an immobilized pepsin column (Fig. 2).

1. Prepare the HDX-MS system: connect the pepsin column, the pre-column and the analytical column to the UPLC system. Set the temperature of the HDX chamber to $0^{\circ} \mathrm{C}$ and equilibrate the column and the pre-column for at least $2 \mathrm{~h}$ with $95 \%$ buffer $\mathrm{A}(0.15 \%$ formic acid, $\mathrm{pH}$ $2.5)$ and $5 \%$ buffer B (100\% acetonitrile, $0.15 \%$ formic acid).

2. Equilibrate the pepsin column with the digestion buffer $(0.15 \%$ formic acid, $\mathrm{pH} 2.5)$. The temperature of the pepsin column can be adjusted to improve the efficacy of the digestion. Low temperatures favor deuterium recovery, but reduce the activity of the enzyme. We generally start to equilibrate the pepsin column at $20^{\circ} \mathrm{C}$.

3. Set the mass spectrometer to MS/MS mode (i.e., either in data-dependent or data-independent acquisition mode; we do recommend using the data-independent acquisition mode $\left(\mathrm{MS}^{\mathrm{E}}\right)$ with the Synapt G2-Si HDMS instrument). Adjust the source conditions (voltages and temperatures) to minimize the back-exchange. Calibrate the instrument.

4. Prepare the membrane protein following the protocol described in Fig. 2 using $\mathrm{H}_{2} \mathrm{O}$ in place of $\mathrm{D}_{2} 0$ solutions (See Note 6).

5. Obtain a preliminary peptide digestion map of the membrane protein. Inject $50 \mu \mathrm{L}$ of quenched sample (8.8 pmols) prepared in $\mathrm{H}_{2} 0$ and perform the digestion for 2 min at $20^{\circ} \mathrm{C}$ and $100 \mu \mathrm{L} / \mathrm{min}$. The quantity of material required per injection mostly depends on the sensitivity of the mass spectrometer used (we do not inject more than 10 pmols on the Synapt G2-Si HDMS in resolution mode). 
6. Elute peptides onto the mass spectrometer using a short gradient of buffer $\mathrm{B}$ at $0^{\circ} \mathrm{C}(e . g ., 5$ to $35 \%$ in 8 min is a good starting point). Perform a quick analysis to generate a preliminary peptide map (See section 3.2, part 3.2.1). Determine the optimal digestion conditions by changing the flow rate and temperature of the pepsin column, and/or the quenching conditions (See Note 7). Carefully adjust the gradient to optimize the separation of peptides from the detergent. Note the $\%$ of acetonitrile required to elute the detergent from the analytical column before adjusting the gradient.

7. Repeat steps 5 to $\mathbf{6}$ with each new gradient.

8. Once the optimized experimental conditions are determined, generate the final peptide map in triplicate. The LC gradient, quench conditions and digestion parameters should remain constant for the rest of the experiment with $\mathrm{D}_{2} 0$ buffer.

[Figure 2 near here]

\subsubsection{Sample preparation}

1. Prepare the labeled samples following the procedure described in Fig. 2 (See Note 8).

2. Place the labeling buffer at room temperature for $1 \mathrm{~h}$ and the quench buffer on ice.

3. Equilibrate your system for $\mathrm{X} \min$ at $\mathrm{T}^{\circ} \mathrm{C}$. This step increases the probability of a uniform protein population, in terms of conformation, dynamics etc., and favors the binding of the ligand (See Note 9). The temperature and time of equilibration depends on the intrinsic stability of the membrane protein (for instance, the DDS-solubilized EEAT1 membrane protein starts to lose its quaternary structure after $2 \mathrm{~h}$ incubation at room temperature).

4. Initiate the labeling by adding an excess of $\mathrm{D}_{2} \mathrm{O}$ buffer. We generally use a 5-fold dilution to reach a final $\mathrm{D}_{2} 0$ ratio of $80 \%$ but other dilution factors may be used (See Note 9). Incubate the samples at the desired temperature. It is common procedure to perform the reaction at room temperature, although other labeling temperatures may be used $\left(\right.$ e.g., $4^{\circ} \mathrm{C}, 15^{\circ} \mathrm{C}, 25^{\circ} \mathrm{C}$ using a thermoblock).

5. At defined periods of time, remove an aliquot of labeled sample and quench the reaction by mixing with an ice cold quench buffer to decrease both the $\mathrm{pH}$ to 2.5 and the temperature to 
$0^{\circ} \mathrm{C}$. Snap-froze samples in liquid nitrogen and stored at $-80^{\circ} \mathrm{C}$ until MS analysis (for less than a week).

6. Prepare one digestion control per condition following the procedure describe in section 3.1.2. This control will serve as a reference to calculate the level of deuterium incorporation per peptide and condition (Section 3.2.1, step 3).

7. Repeat steps $\mathbf{3}$ to $\mathbf{5}$ to generate independent technical replicates. Triplicates are required to perform statistical analysis.

\subsubsection{MS-Data acquisition}

1. Prepare the mass spectrometer and HDX-system as described in section 3.1.2 (steps 1 to 3). Set the mass spectrometer in MS acquisition mode and perform a new calibration. If using a Synapt G2-Si mass spectrometer, carefully adjust the StepWave and Source settings to reduce gas-phase deuterium loss and bimodal artefacts [35].

2. Before starting any injection, place a glass syringe (Hamilton $100 \mu \mathrm{L} 710 \mathrm{SNR}, 22 \mathrm{~s}$ Gauge, Point style 3) on ice for a minimum of $10 \mathrm{~min}$.

3. Thaw one sample and immediately inject $50 \mu \mathrm{L}$ into the cooled HDX system using the chilled glass syringe. Proceed to the digestion, peptide separation and MS acquisition using the conditions defined in section 3.1.2, step 8 .

4. At the end of each run, clean the pepsin column with two consecutive injections of pepsin wash solution maintained at room temperature (See Note 10).

5. Perform a blank between each run to confirm the absence of carry-over (See Note 11).

\subsection{From Data Extraction to Statistical Validation and Data interpretation}

\subsubsection{HDX-MS data extraction using Waters software}

1. Obtain the peptide map with PLGS using the default E-MS ${ }^{\mathrm{E}}$ processing parameters (Low Energy Threshold: 250 counts; Elevated Energy Threshold: 100 counts; Intensity Threshold: 750 counts). Adjust the Low and Elevated Energy thresholds based on the MS signal intensity 
(the default values represent a good starting point). Control the assignment of each fragmentation spectrum. Automatically generate the output file in .csv by clicking the Ion Accounting Output option in the IdentityE tab of the Automation Setup to "On".

2. Load the .csv file in DynamX 3.0 and refine the peptide map using a minimum product per amino-acid value of 0.4. Load all deuterated MS data and adjust the ion detection threshold (default value sets at 130) based on the spectral quality (Fig. 3A).

3. DynamX 3.0 automatically extracts the relative deuterium uptake values for each peptide and condition and generates the deuterium uptake plots. For each peptide, control the spectral quality and the peak picking.

4. Select one unique charge state per peptide to perform the statistical analysis with MEMHDX. Export the results in .csv using the CLUSTER export option in DynamX (MEMHDX does not run with STATE data) (See Note 12).

[Figure 3 near here]

\subsubsection{Statistical validation with MEMHDX}

1. Open the .csv file (CLUSTER data) in Excel. Your file MUST contain the following variables (all other variables can be removed from the .csv file, if needed):
a. Start: Peptide Start position on the protein
b. End: Peptide End position on the protein
c. Sequence: Peptide Sequence
d. State: Name of the conditions.
e. Exposure: Value of the exposure time ( $\mathrm{min})$
f. Replicate: Replicate number $(n>=3)$
g. $z$ : Peptide charge state
h. Center: Centroid $m / z$ value

i. MaxUptake: Maximum number of exchangeable amide hydrogens per peptide. 
2. Create the column "Replicate" and complete with the corresponding number (i.e., 1, 2,.., n). A minimum of three independent replicates is required (See Note 13). Check the .csv file before proceeding to the next step (i.e., number of replicates and conditions etc.). Please note that at least one exposure time is required for each peptide, charge state and condition.

3. Go to the MEMHDX web site (http://memhdx.c3bi.pasteur.fr).

4. Go to the Start Analysis panel at the top of the application and upload the .csv file. MEMHDX automatically controls the global architecture of the .csv and the presence of each variable.

5. Adjust the MEMHDX options ( $p$-value, $\% \mathrm{D}_{2} 0$ and Biological Threshold; the default values can be used as a starting point and adjusted later) and run the analysis.

6. In the HDX-MS results section, go to the Global Overview panel and explore your HDX-MS results using the different panels (Box plot, PCA and Clustering). Pay particular attention to the quality control of the whole HDX-MS dataset (Fig. 3B). The box plot representation summarizes the variability across replicates and considers the deuterium values measured for all peptides, and at each time point. It is a good indication of the reproducibility between replicates. The Principal Component Analysis $(P C A)$ summarizes the effects of the variance on the entire datasets independent of either the conditions or labeling time.

7. Go to the Peptide plot panel and analyze the fitting quality of the model for each peptide. Peptides can be sorted by fitting quality (log-likelihood), or by position (from N- to Cterminal), and further excluded from the statistical analysis using the "remove" button (Fig. 3C).

8. Go to the Logit plot panel to identify statistically significant peptides (Fig. 3C). The $p$-value, biological threshold and $\% \mathrm{D}_{2} 0$ can be adjusted during the analysis.

\subsubsection{Visualization and interpretation}

1. Use the "Global visualization" tool in MEMHDX to display the final HDX results. MEMHDX automatically plots the relative fractional uptake values (normalized values independent of the peptide length) as a function of peptide position and for each condition 
(e.g., free versus bound state). This representation gives both spatial and temporal information on the HDX behavior of the protein (Fig. 4A).

2. Identify peptides with statistically significant differences of deuterium uptake between states using the Fractional Uptake Difference plot (Fig. 4B). Statistically significant peptides are highlighted in light blue.

3. Interpret the HDX results in light of the crystal structure of the protein (Fig. 4C) (See Note 14).

[Figure 4 near here]

\section{Conclusions}

The HDX-MS protocol described in this chapter should be applicable to any membrane protein solubilized in "MS-friendly" detergents, upon careful selection of the quench conditions and optimization of the chromatographic separation. The DDS detergent utilized in this procedure does not affect the chromatographic system, as most of the detergent is eluted from the C18 analytical column at the end of the gradient. However, assays performed with DDM are less satisfactory in our hands, due to the incomplete elution of the detergent leading to a slow but constant increase of the column pressure with time and injections. Change of the pre-column and/or overnight back flushes of the analytical column at room temperature with mixtures of methanol/acetonitrile are therefore required from time to time to avoid overpressure of the chromatographic system and loss of deuterated samples.

Although detergent micelles facilitate the extraction, solubilization and characterization of integral membrane proteins, they constitute poor mimics of the native membrane, putting into doubt the biological significance of results obtained in their presence. HDX-MS protocols are now quickly evolving to investigate the conformation and dynamics of membrane proteins reconstituted in more "native-like" environments, such as those using liposomes or nanodiscs [36-41]. One elegant example of this is a recent HDX-compatible protocol that has been developed and applied to the analysis of prokaryotic integral membrane proteins in native conditions [42]. 


\section{Notes}

1. The labeling buffer is directly prepared in the $25 \mathrm{~g} \mathrm{D}_{2} \mathrm{O}$ bottle. $25 \mathrm{~g}$ of $\mathrm{D}_{2} 0$ corresponds to a final volume of $22.6 \mathrm{~mL}$ at $25^{\circ} \mathrm{C}\left(\right.$ density $\left.=1.107 \mathrm{~g} / \mathrm{cm}^{3}\right)$. Once all components have been weight and dissolved in the $\mathrm{D}_{2} 0$ bottle, the $\mathrm{pH}$ is adjusted to the desired value using either concentrated $\mathrm{DCl}(\sim 12 \mathrm{M})$ or $\mathrm{NaOD}(\sim 14 \mathrm{M})$. Working solutions of $\mathrm{DCl}$ and $\mathrm{NaOD}$ are prepared by dilution in $\mathrm{D}_{2} 0$. Keep in mind that the $\mathrm{pH}_{\text {reading }}$ of a deuterated solution is 0.4 units lower than $\mathrm{pD}$ when using a classical hydrogen electrode (i.e., a $\mathrm{pH}_{\text {reading }}$ of 7.0 corresponds to a pD value of 7.4).

2. "MS-compatible" detergents only refer to acid-labile surfactants such as RapiGest SF (Waters Corporation) or surfactant capable to degrade with time such as ProteaseMAX (Promega).

These surfactants are commonly used in the preparation of classical proteomics samples.

3. The concentration of the cross-linked pepsin on agarose beads is unknown. The manufacturer recommends using $125 \mu \mathrm{L}$ of settled resin to digest $10 \mathrm{mg}$ of IgG. The guard column can accommodate $63 \mu \mathrm{L}$ of the $50 \%$ slurry (i.e., $31.5 \mu \mathrm{L}$ of settled resin) and thus handle up to 2.5 $\mathrm{mg}$ of protein per run (the quantity of injected material per assay should be in the $\mu \mathrm{g}$ range).

4. It is good practice to control the activity of your pepsin column before beginning to inject your protein samples. In our lab, we assess the activity of the column by injecting a known reference sample (Bet v 1; UniprotKB access number \# P15494) prepared in $0.15 \%$ formic acid at $0.2 \mu \mathrm{M}$ (10 pmols per injection (i.e., $0.17 \mu \mathrm{g}$ ), triplicate analysis). The elution profiles, spectral quality, and MS/MS data of each acquisition are compared to previous acquisitions performed in the exact same conditions to evaluate the activity and performance of the new pepsin column.

5. Digestions can take place online with immobilized acidic proteases packed into a column or offline (i.e., in solution) using solubilized acidic proteases or acidic protease immobilized on a solid support (POROS-20AL beads etc.). Offline digestions are normally performed on ice to reduce back-exchange, thus increasing the time of digestion. In addition, the protein:acidic protease ratio must be optimized: a 1:1 (w:w) ratio is generally sufficient with pig pepsin 
whereas higher ratios are required with type XIII and type XVIII proteases from Aspergillus saitoi and Rhizopus species [43]. Although solubilized acidic proteases work well in solution, we do recommend immobilized acidic proteases for both online and offline digestions to reduce the time of digestion and to introduce more flexibility in the final composition of the quench buffer (See Note 7).

6. Before preparing and injecting your detergent-solubilized membrane protein prepared in $\mathrm{H}_{2} \mathrm{O}$, we highly recommend evaluating the effects of the detergent and other molecules (i.e., small ligands) on the activity of the pepsin column using a known protein sample prepared in the exact same conditions. In our lab, we use the Bet v 1 protein to evaluate the effects of distinct components of the digestion step. For instance, we noticed that 0.02\% (w:v) DDM in the quench buffer reduces the activity of the pepsin column (presence of undigested material at the end of the gradient).

7. Optimization of the quench conditions is essential to generate the best sequence coverage possible and depends on the protein and the labeling conditions (i.e., buffer composition etc.). The group of Patrick R. Griffith [30] elegantly showed how to select and optimize quench conditions to study the dynamics of the $\beta 2$-adrenergic G-protein coupled receptor. If the detergent-solubilized membrane protein contains disulfide bridges, then reducing agents such as TCEP can be added to the quench buffer. Electrochemical reduction using a $\mu$-PrepCell thin-layer electrochemical reactor cell (Antec, Zoeterwoude, NL) may also be considered $[44,45]$. In addition, some proteins might not digest very well using standard quench conditions. In this scenario, chaotropic agents such as guanidinium chloride or urea may be used to favor the denaturation of proteins. In our hands, $4 \mathrm{M}$ urea works very well when performing online digestion. Bear in mind that solubilized acidic proteases are less resistant to chaotropic or reducing agents than immobilized enzymes.

8. Sample handling can be automated using a dedicated PAL-HDX autosampler [46].

9. The concentration of the detergent-solubilized membrane protein and the ligand must be carefully selected to avoid disruption of complexes during labeling. A good starting point is to fix the concentration of the detergent-solubilized membrane protein based on the MS-signal 
quality and intensity of peptides obtained after digestion. The Kd value is then used to adjust the concentration of ligands so that $>90 \%$ of the complex remains formed before and after dilution with the labeling buffer. Please note that this calculation must take into account the stoichiometry of the binding reaction. For the binding of UCPH-101 with EAAT1 (Kd $~ 4.5$ $\mu \mathrm{M}$; binding stoichiometry $=1$ ), a 1:20 molar ratio was used to complex $95.5 \%$ of EAAT1 before labelling (Fig. 2). The concentration (in $\mu \mathrm{M}$ ) and $\%$ of complex were calculated using the following equations:

$$
\begin{gathered}
{[\text { Complexe }]=\frac{\left(\text { Kd }+[\text { Protein }]+[\text { Ligand }]+\sqrt{(\text { Kd }+[\text { Protein }]+[\text { Ligand }])^{2}-4([\text { Protein }] \cdot[\text { Ligand }])}\right.}{2}} \\
\% \text { Complexe }=\frac{[\text { Complexe }]}{[\text { Protein }]}
\end{gathered}
$$

In addition, UCPH-101 was added to the labeling buffer to match the initial concentration of ligand during equilibration and prevent dissociation of the complex. If the $\mathrm{Kd}$ is not available, a 1:10 molar ratio (protein:ligand) represents a good starting point (depending on the tolerance of the pepsin column and the effect of the ligand of the MS signal).

10. This washing step should be performed to avoid carryover from previous samples. In most cases, the carryover is due to incomplete elution from the pepsin column leading to a false EX1 signature. One way to minimize the carryover is to add small quantities of detergent in the quench buffer [34], or to perform several extra washes of the acidic protease column with chaotropic agents such as guanidinium chloride (the concentration of guanidinium chloride should not exceed 2M) [47].

11. In order to identify "sticky peptides", blank injections should be performed with the same elution gradient than that of the deuterated samples. We highly recommend introducing rapid sawtooth gradient cycles at the end of the analytical gradient to wash and regenerate the column. We generally perform two sawtooth cycles (Table 1) before equilibrating the column to pre-injection conditions; the rapid changes of pressure of the system during these cycles also favour the elution of the remaining traces of detergent. [Table 1 here] 
12. We use the bioinformatics solution provided by Waters (PLGS, MassLynX and DynamX) to identify peptides, extract deuterium uptake values, and analyze our results. Other bioinformatics solutions exist for this purpose [48].

13. The cluster . csv file of DynamX does not contain the "replicate" column requires to run MEMHDX. Adding the replicate value in front of each time point and condition is a time consuming task that we avoid by adding the replicate number at the end of each acquisition file name. We then use the convert function in Excel to automatically generate the "replicate" column.

14. HDX results can be analyzed in the absence of any crystal or NMR structure but the strength and confidence of the interpretation is greatly reduced. For instance, the binding of a ligand is expected to reduce the solvent accessibility of backbone amide hydrogens located at or near the binding site only. However, allosteric changes might occur upon binding thus leading to additional changes of accessibility in regions distal from the interaction site. Alternatively, the interaction sites might be formed by discontinuous segments of the protein, as observed with conformational epitopes $[49,8,14]$.

\section{Acknowledgments}

The HDX-MS system was financed by the Equipex CACSICE (ANR-11-EQPX-0008). SB would like to thank Alexandre Chenal, Nadia Izadi-Prunyere, Mariette Matondo, Thierry Lang, Daniel Ladant, and Michael Nilges for their kindness and constant support over the last year.

\section{Figure legends}

Fig. 1. Workflow of a typical HDX experiment. (A). The detergent-solubilized membrane protein is equilibrated in specific conditions (+/- ligands, presence of perturbants, etc.) at the desired temperature and for a specified amount of time. The labeling starts by adding a large excess of deuterated buffer. At defined periods, the reaction is quenched by decreasing both the $\mathrm{pH}$ and the temperature, to 2.5 and $0^{\circ} \mathrm{C}$. The quenching conditions "freeze" the protein in a specific labeling state by decreasing the exchange rate constant by five orders of magnitude. (B-C). Quenched samples can 
be immediately snap-frozen and conserved at $-80^{\circ} \mathrm{C}$ or digested either on line with an immobilized pepsin column or in solution. Peptides are further separated at $0^{\circ} \mathrm{C}$ by reverse phase chromatography using an optimized gradient of acetonitrile and directly analyzed by MS.

Fig. 2. Schematic showing the different steps followed to prepare the deuterated EAAT1 samples in the presence and absence of UCPH-101. The DDS-solubilized EAAT1 membrane protein is incubated for $30 \mathrm{~min}$ on ice in the presence and absence of an excess of UCPH-101 and 2.2\% final DMSO. Following an additional 10 min equilibration time at room temperature, the labeling is initiated by a 5-fold dilution with the deuterated buffer. The concentration of the protein and the ligand were carefully selected and adjusted so that $~ 95.5 \%$ of the EAAT1 protein remains bound to the ligand before and after labeling (assuming a Kd value of $\sim 4.5 \mu \mathrm{M}$ ) (See Note 9). At defined time points, the reaction is quenched by mixing $10 \mu \mathrm{L}$ of labeled samples (10.6 pmols of EAAT1) with $50 \mu \mathrm{L}$ of an ice-cold quenching solution. Quenched samples are immediately snapfrozen in liquid nitrogen and stored at $-80^{\circ} \mathrm{C}$.

Fig. 3. Data extraction and statistical validation. (A) The initial peptide map is generated with PLGS and further refined in DynamX. The relative deuterium uptake values measured for each peptide and condition and at each time point are automatically extracted by DynamX and plotted as a function of incubation time. (B). Global statistical analysis is performed by MEMHDX on the entire HDX dataset. The boxplot representation summarizes variability across replicates and conditions. (C) The local statistical analysis is only initiated after validation of the whole HDX-MS dataset. The peptide plot panel of MEMHDX displays the results generated per peptide and shows the fitting quality of the mixed-effects model. Once each peptide has been inspected, the LogitPlot is used to summarize and identify all statistically significant peptides.

Fig. 4. Visualization of the HDX results with MEMHDX. (A). Relative fractional uptake plots obtained with the detergent solubilized EAAT1 membrane protein alone (Control plot) or in the 
presence of a $\sim 20$-fold molar excess of ligand (UCPH-101). Each dot corresponds to an average of three independent technical replicates. (B). Fractional uptake difference plot showing the difference in deuterium uptake calculated between the ligand-bound and free EAAT1 protein. Negative values indicate a ligand-induced reduction of solvent accessibility. Statistically significant peptides are highlighted in light blue (Wald test; $p<0.05$ ). (C). Visualization of the HDX-MS results on the crystal structure of EAAT1 (pdb \# 5LM4) [12]. 


\section{References}

1. Jaswal SS (2013) Biological insights from hydrogen exchange mass spectrometry. Biochimica et biophysica acta 1834 (6):1188-1201. doi:10.1016/j.bbapap.2012.10.011

2. Konermann L, Pan J, Liu YH (2011) Hydrogen exchange mass spectrometry for studying protein structure and dynamics. Chemical Society reviews 40 (3):1224-1234. doi:10.1039/c0cs00113a 3. Oganesyan I, Lento C, Wilson DJ (2018) Contemporary hydrogen deuterium exchange mass spectrometry. Methods 144:27-42. doi:10.1016/j.ymeth.2018.04.023

4. Tsutsui Y, Wintrode PL (2007) Hydrogen/deuterium exchange-mass spectrometry: a powerful tool for probing protein structure, dynamics and interactions. Current medicinal chemistry 14 (22):23442358

5. Wales TE, Engen JR (2006) Hydrogen exchange mass spectrometry for the analysis of protein dynamics. Mass spectrometry reviews 25 (1):158-170. doi:10.1002/mas.20064

6. Brier S, Engen JR (2008) Hydrogen Exchange Mass Spectrometry: Principles and Capabilities. In: Chance M (ed) Mass Spectrometry Analysis for Protein-Protein Interactions and Dynamics. John Wiley \& Sons, pp 11-43

7. Brier S, Fagnocchi L, Donnarumma D, Scarselli M, Rappuoli R, Nissum M, Delany I, Norais N (2012) Structural insight into the mechanism of DNA-binding attenuation of the Neisserial adhesin repressor NadR by the small natural ligand 4-hydroxyphenylacetic acid. Biochemistry 51 (34):67386752. doi:10.1021/bi300656w

8. Faleri A, Santini L, Brier S, Pansegrau W, Lo Surdo P, Scarselli M, Buricchi F, Volpini G, Genovese A, van der Veen S, Lea S, Tang CM, Savino S, Pizza M, Finco O, Norais N, Masignani V (2014) Two cross-reactive monoclonal antibodies recognize overlapping epitopes on Neisseria meningitidis factor $\mathrm{H}$ binding protein but have different functional properties. FASEB journal : official publication of the Federation of American Societies for Experimental Biology 28 (4):16441653. doi:10.1096/fj.13-239012

9. Georgescauld F, Popova K, Gupta AJ, Bracher A, Engen JR, Hayer-Hartl M, Hartl FU (2014) GroEL/ES chaperonin modulates the mechanism and accelerates the rate of TIM-barrel domain folding. Cell 157 (4):922-934. doi:10.1016/j.cell.2014.03.038

10. Pirrone GF, Emert-Sedlak LA, Wales TE, Smithgall TE, Kent MS, Engen JR (2015) MembraneAssociated Conformation of HIV-1 Nef Investigated with Hydrogen Exchange Mass Spectrometry at a Langmuir Monolayer. Analytical chemistry 87 (14):7030-7035. doi:10.1021/acs.analchem.5b01725 11. Trelle MB, Dupont DM, Madsen JB, Andreasen PA, Jorgensen TJ (2014) Dissecting the effect of RNA aptamer binding on the dynamics of plasminogen activator inhibitor 1 using hydrogen/deuterium exchange mass spectrometry. ACS chemical biology 9 (1):174-182. doi: $10.1021 / \mathrm{cb} 400619 \mathrm{v}$

12. Canul-Tec JC, Assal R, Cirri E, Legrand P, Brier S, Chamot-Rooke J, Reyes N (2017) Structure and allosteric inhibition of excitatory amino acid transporter 1. Nature 544 (7651):446-451.

doi:10.1038/nature22064

13. Chung KY, Rasmussen SG, Liu T, Li S, DeVree BT, Chae PS, Calinski D, Kobilka BK, Woods VL, Jr., Sunahara RK (2011) Conformational changes in the G protein Gs induced by the beta2 adrenergic receptor. Nature 477 (7366):611-615. doi:10.1038/nature10488

14. Malito E, Faleri A, Lo Surdo P, Veggi D, Maruggi G, Grassi E, Cartocci E, Bertoldi I, Genovese A, Santini L, Romagnoli G, Borgogni E, Brier S, Lo Passo C, Domina M, Castellino F, Felici F, van der Veen S, Johnson S, Lea SM, Tang CM, Pizza M, Savino S, Norais N, Rappuoli R, Bottomley MJ, Masignani V (2013) Defining a protective epitope on factor H binding protein, a key meningococcal virulence factor and vaccine antigen. Proceedings of the National Academy of Sciences of the United States of America 110 (9):3304-3309. doi:10.1073/pnas.1222845110

15. O'Brien DP, Brier S, Ladant D, Durand D, Chenal A, Vachette P (2018) SEC-SAXS and HDXMS: A powerful combination. The case of the calcium-binding domain of a bacterial toxin.

Biotechnology and applied biochemistry 65 (1):62-68. doi:10.1002/bab.1577

16. O'Brien DP, Durand D, Voegele A, Hourdel V, Davi M, Chamot-Rooke J, Vachette P, Brier S, Ladant D, Chenal A (2017) Calmodulin fishing with a structurally disordered bait triggers CyaA catalysis. PLoS biology 15 (12):e2004486. doi:10.1371/journal.pbio.2004486 
17. Cavaliere P, Brier S, Filipenko P, Sizun C, Raynal B, Bonnete F, Levi-Acobas F, Bellalou J, England P, Chamot-Rooke J, Mayer C, Norel F (2018) The stress sigma factor of RNA polymerase $\mathrm{RpoS} /$ sigma(S) is a solvent-exposed open molecule in solution. The Biochemical journal 475 (1):341354. doi:10.1042/BCJ20170768

18. Hamdi K, Salladini E, O'Brien DP, Brier S, Chenal A, Yacoubi I, Longhi S (2017) Structural disorder and induced folding within two cereal, ABA stress and ripening (ASR) proteins. Scientific reports 7 (1):15544. doi:10.1038/s41598-017-15299-4

19. Wales TE, Fadgen KE, Gerhardt GC, Engen JR (2008) High-speed and high-resolution UPLC separation at zero degrees Celsius. Analytical chemistry 80 (17):6815-6820. doi:10.1021/ac8008862 20. Hourdel V, Volant S, O'Brien DP, Chenal A, Chamot-Rooke J, Dillies MA, Brier S (2016) MEMHDX: an interactive tool to expedite the statistical validation and visualization of large HDXMS datasets. Bioinformatics 32 (22):3413-3419. doi:10.1093/bioinformatics/btw420

21. Miller DE, Prasannan CB, Villar MT, Fenton AW, Artigues A (2012) HDXFinder: automated analysis and data reporting of deuterium/hydrogen exchange mass spectrometry. Journal of the American Society for Mass Spectrometry 23 (2):425-429. doi:10.1007/s13361-011-0234-5 22. Pascal BD, Chalmers MJ, Busby SA, Mader CC, Southern MR, Tsinoremas NF, Griffin PR (2007) The Deuterator: software for the determination of backbone amide deuterium levels from H/D exchange MS data. BMC bioinformatics 8:156. doi:10.1186/1471-2105-8-156

23. Pascal BD, Willis S, Lauer JL, Landgraf RR, West GM, Marciano D, Novick S, Goswami D, Chalmers MJ, Griffin PR (2012) HDX workbench: software for the analysis of H/D exchange MS data. Journal of the American Society for Mass Spectrometry 23 (9):1512-1521. doi:10.1007/s13361012-0419-6

24. Lim XX, Chandramohan A, Lim XY, Bag N, Sharma KK, Wirawan M, Wohland T, Lok SM, Anand GS (2017) Conformational changes in intact dengue virus reveal serotype-specific expansion. Nature communications 8:14339. doi:10.1038/ncomms 14339

25. Giladi M, Almagor L, van Dijk L, Hiller R, Man P, Forest E, Khananshvili D (2016) Asymmetric Preorganization of Inverted Pair Residues in the Sodium-Calcium Exchanger. Scientific reports 6:20753. doi:10.1038/srep20753

26. Giladi M, van Dijk L, Refaeli B, Almagor L, Hiller R, Man P, Forest E, Khananshvili D (2017) Dynamic distinctions in the $\mathrm{Na}(+) / \mathrm{Ca}(2+)$ exchanger adopting the inward- and outward-facing conformational states. The Journal of biological chemistry 292 (29):12311-12323. doi:10.1074/jbc.M117.787168

27. Mehmood S, Domene C, Forest E, Jault JM (2012) Dynamics of a bacterial multidrug ABC transporter in the inward- and outward-facing conformations. Proceedings of the National Academy of Sciences of the United States of America 109 (27):10832-10836. doi:10.1073/pnas.1204067109 28. West GM, Chien EY, Katritch V, Gatchalian J, Chalmers MJ, Stevens RC, Griffin PR (2011) Ligand-dependent perturbation of the conformational ensemble for the GPCR beta2 adrenergic receptor revealed by HDX. Structure 19 (10):1424-1432. doi:10.1016/j.str.2011.08.001 29. Yang L, Yang D, de Graaf C, Moeller A, West GM, Dharmarajan V, Wang C, Siu FY, Song G, Reedtz-Runge S, Pascal BD, Wu B, Potter CS, Zhou H, Griffin PR, Carragher B, Yang H, Wang MW, Stevens RC, Jiang H (2015) Conformational states of the full-length glucagon receptor. Nature communications 6:7859. doi:10.1038/ncomms8859

30. Zhang X, Chien EY, Chalmers MJ, Pascal BD, Gatchalian J, Stevens RC, Griffin PR (2010) Dynamics of the beta2-adrenergic G-protein coupled receptor revealed by hydrogen-deuterium exchange. Analytical chemistry 82 (3):1100-1108. doi:10.1021/ac902484p

31. Antharavally BS, Mallia KA, Rosenblatt MM, Salunkhe AM, Rogers JC, Haney P, Haghdoost N (2011) Efficient removal of detergents from proteins and peptides in a spin column format. Analytical biochemistry 416 (1):39-44. doi:10.1016/j.ab.2011.05.013

32. Wisniewski JR, Zougman A, Nagaraj N, Mann M (2009) Universal sample preparation method for proteome analysis. Nature methods 6 (5):359-362. doi:10.1038/nmeth.1322

33. Cirri E, Brier S, Assal R, Canul-Tec JC, Chamot-Rooke J, Reyes N (2018) Consensus designs and thermal stability determinants of a human glutamate transporter. eLife 7. doi:10.7554/eLife.40110 34. Hamuro Y, Coales SJ (2018) Optimization of Feasibility Stage for Hydrogen/Deuterium Exchange Mass Spectrometry. Journal of the American Society for Mass Spectrometry 29 (3):623629. doi:10.1007/s13361-017-1860-3 
35. Guttman M, Wales TE, Whittington D, Engen JR, Brown JM, Lee KK (2016) Tuning a High Transmission Ion Guide to Prevent Gas-Phase Proton Exchange During H/D Exchange MS Analysis. Journal of the American Society for Mass Spectrometry 27 (4):662-668. doi:10.1007/s13361-015$1330-8$

36. Adhikary S, Deredge DJ, Nagarajan A, Forrest LR, Wintrode PL, Singh SK (2017) Conformational dynamics of a neurotransmitter:sodium symporter in a lipid bilayer. Proceedings of the National Academy of Sciences of the United States of America 114 (10):E1786-E1795. doi:10.1073/pnas.1613293114 37. Hebling CM, Morgan CR, Stafford DW, Jorgenson JW, Rand KD, Engen JR (2010) Conformational analysis of membrane proteins in phospholipid bilayer nanodiscs by hydrogen exchange mass spectrometry. Analytical chemistry 82 (13):5415-5419. doi:10.1021/ac100962c 38. Morgan CR, Hebling CM, Rand KD, Stafford DW, Jorgenson JW, Engen JR (2011) Conformational transitions in the membrane scaffold protein of phospholipid bilayer nanodiscs. Molecular \& cellular proteomics : MCP 10 (9):M111 010876. doi:10.1074/mcp.M111.010876 39. Parker CH, Morgan CR, Rand KD, Engen JR, Jorgenson JW, Stafford DW (2014) A conformational investigation of propeptide binding to the integral membrane protein gamma-glutamyl carboxylase using nanodisc hydrogen exchange mass spectrometry. Biochemistry 53 (9):1511-1520. doi:10.1021/bi401536m

40. Redhair M, Clouser AF, Atkins WM (2019) Hydrogen-Deuterium Exchange Mass Spectrometry of Membrane Proteins in Lipid Nanodiscs. Chemistry and physics of lipids.

doi:10.1016/j.chemphyslip.2019.02.007

41. Vahidi S, Bi Y, Dunn SD, Konermann L (2016) Load-dependent destabilization of the gammarotor shaft in FOF1 ATP synthase revealed by hydrogen/deuterium-exchange mass spectrometry. Proceedings of the National Academy of Sciences of the United States of America 113 (9):2412-2417. doi:10.1073/pnas.1520464113

42. Donnarumma D, Maestri C, Giammarinaro PI, Capriotti L, Bartolini E, Veggi D, Petracca R, Scarselli M, Norais N (2018) Native State Organization of Outer Membrane Porins Unraveled by HDx-MS. Journal of proteome research 17 (5):1794-1800. doi:10.1021/acs.jproteome.7b00830 43. Cravello L, Lascoux D, Forest E (2003) Use of different proteases working in acidic conditions to improve sequence coverage and resolution in hydrogen/deuterium exchange of large proteins. Rapid communications in mass spectrometry : RCM 17 (21):2387-2393. doi:10.1002/rcm.1207 44. Mysling S, Salbo R, Ploug M, Jorgensen TJ (2014) Electrochemical reduction of disulfidecontaining proteins for hydrogen/deuterium exchange monitored by mass spectrometry. Analytical chemistry 86 (1):340-345. doi:10.1021/ac403269a 45. Trabjerg E, Jakobsen RU, Mysling S, Christensen S, Jorgensen TJ, Rand KD (2015) Conformational analysis of large and highly disulfide-stabilized proteins by integrating online electrochemical reduction into an optimized H/D exchange mass spectrometry workflow. Analytical chemistry 87 (17):8880-8888. doi:10.1021/acs.analchem.5b01996

46. Forest E, Man P (2016) Conformational Dynamics and Interactions of Membrane Proteins by Hydrogen/Deuterium Mass Spectrometry. Methods in molecular biology 1432:269-279.

doi:10.1007/978-1-4939-3637-3_17

47. Majumdar R, Manikwar P, Hickey JM, Arora J, Middaugh CR, Volkin DB, Weis DD (2012) Minimizing carry-over in an online pepsin digestion system used for the H/D exchange mass spectrometric analysis of an IgG1 monoclonal antibody. Journal of the American Society for Mass Spectrometry 23 (12):2140-2148. doi:10.1007/s13361-012-0485-9

48. Claesen J, Burzykowski T (2017) Computational methods and challenges in hydrogen/deuterium exchange mass spectrometry. Mass spectrometry reviews 36 (5):649-667. doi:10.1002/mas.21519 49. Brier S, Le Mignon M, Jain K, Lebrun C, Peurois F, Kellenberger C, Bordas-Le Floch V, Mascarell L, Nony E, Moingeon P (2018) Characterization of epitope specificities of reference antibodies used for the quantification of the birch pollen allergen Bet v 1. Allergy 73 (5):1032-1040. doi:10.1111/all.13364 
Table 1: Example of HDX-MS gradient profile with two sawtooth cycles

\begin{tabular}{|c|c|c|c|c|}
\hline $\begin{array}{l}\text { Time } \\
(\text { min) }\end{array}$ & $\begin{array}{l}\text { Flow rate } \\
(\mu \mathrm{l} / \mathrm{min})\end{array}$ & $\begin{array}{l}\text { Buffer A } \\
(\%)\end{array}$ & $\begin{array}{l}\text { Buffer B } \\
(\%)\end{array}$ & \\
\hline Initial & 40 & 95 & 5 & \\
\hline $\begin{array}{l}8.00 \\
10.00\end{array}$ & $\begin{array}{l}40 \\
40\end{array}$ & $\begin{array}{l}70 \\
60\end{array}$ & $\begin{array}{l}30 \\
40\end{array}$ & 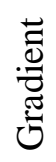 \\
\hline 10.50 & 40 & 5 & 95 & \\
\hline 11.00 & 40 & 5 & 95 & $\approx$ \\
\hline 11.10 & 40 & 95 & 5 & : \\
\hline 12.10 & 40 & 95 & 5 & 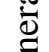 \\
\hline 12.20 & 40 & 5 & 95 & $\overline{\mathbb{D}_{0}}$ \\
\hline 13.20 & 40 & 5 & 95 & $\simeq$ \\
\hline 13.30 & 40 & 95 & 5 & Z \\
\hline 14.30 & 40 & 95 & 5 & $\begin{array}{l}\bar{\sigma} \\
\text { bo }\end{array}$ \\
\hline 14.40 & 40 & 5.0 & 95 &.$\Xi$ \\
\hline 15.40 & 40 & 5.0 & 95 & $\frac{\pi}{\pi}$ \\
\hline 15.5 & 40 & 95 & 5 & 3 \\
\hline 18.0 & 40 & 95 & 5 & \\
\hline
\end{tabular}


Fig. 1.

A. Sample Preparation

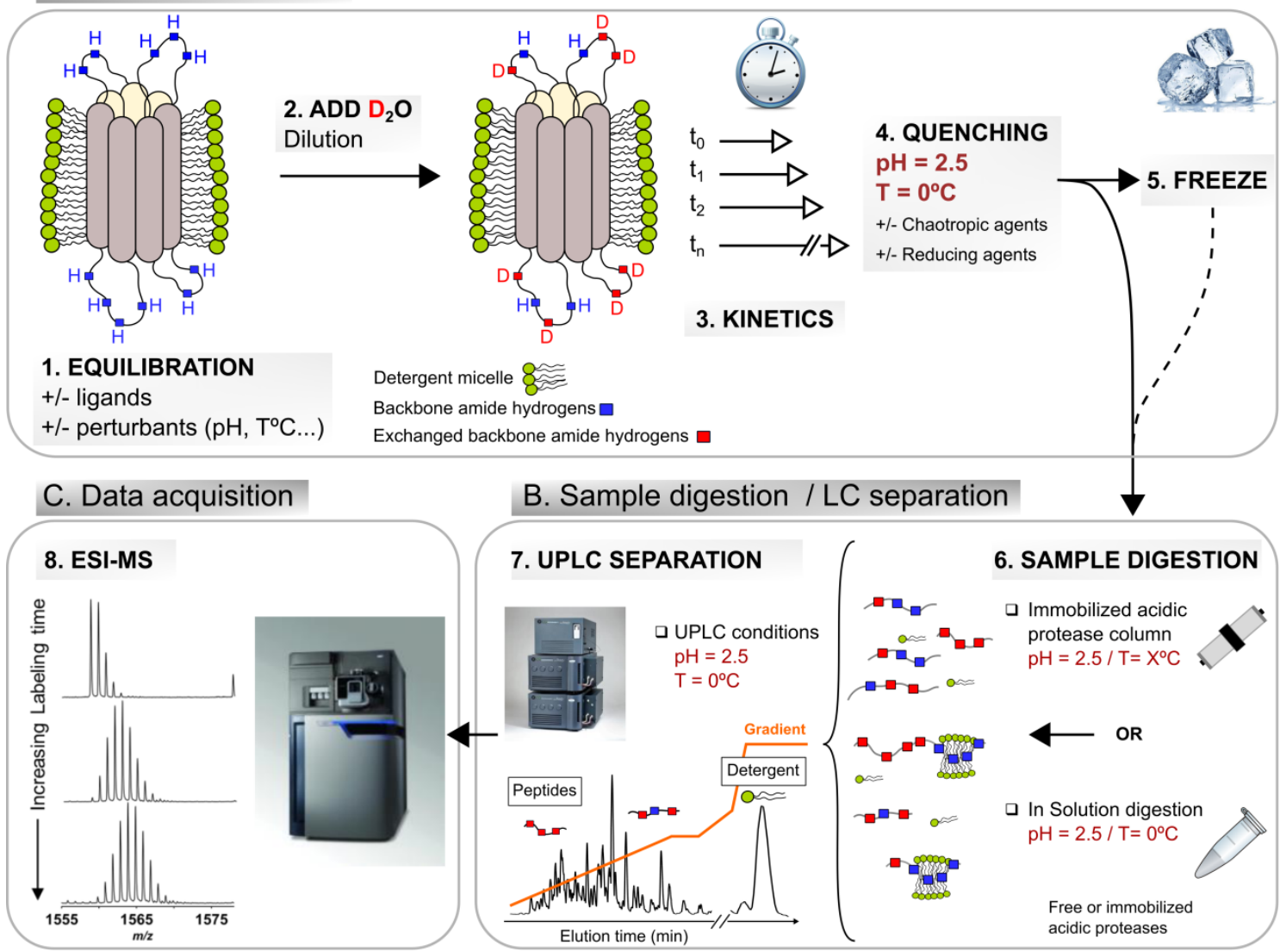


Fig. 2.

Unbound

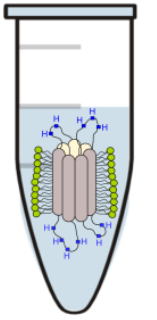

$19.5 \mu \mathrm{L}$ EAAT1 @ $5.3 \mu \mathrm{M}$ $0.5 \mu \mathrm{L}$ DMSO

\section{Ligand-bound}

Initial Conditions

EAAT1: $5.18 \mu \mathrm{M}$

UCPH-101 : $102 \mu \mathrm{M}$

DDS : 0.06\%

CHS : $~ 0.013 \%$

DMSO: 2.2\%

$\mathrm{pH}: \mathbf{7 . 4}$

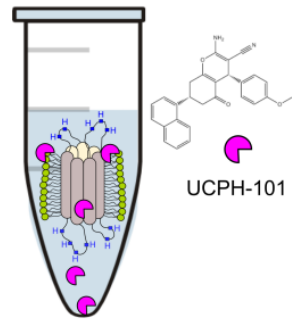

$19.5 \mu \mathrm{L}$ EAAT1 @ $5.3 \mu \mathrm{M}$

$0.5 \mu \mathrm{L}$ UCPH-101 @ 4.6 mM in DMSO

$\%$ complex : $95.5 \%$ (in $20 \mu \mathrm{L}$ )

Incubate on ice for 30 min to allow complex formation and then $10 \mathrm{~min}$ at room temperture prior labeling

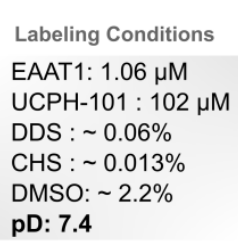

Labeling Conditions

EAAT1: $1.06 \mu \mathrm{M}$

UCPH-101: $102 \mu \mathrm{M}$

DDS : 0.06\%

CHS : $\sim 0.013 \%$

DMSO: 2.2\%

pD: 7.4

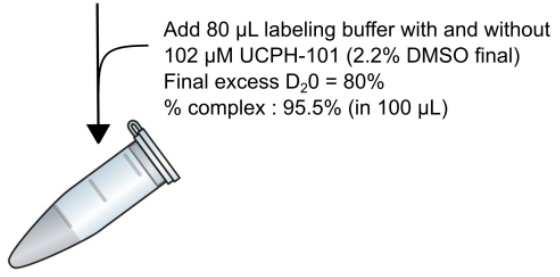

Incubate at room temperature for $\mathrm{t}=10 \mathrm{~s}, \ldots, \mathrm{y}$ min

Remove $10 \mu \mathrm{L}$ of

labeled sample

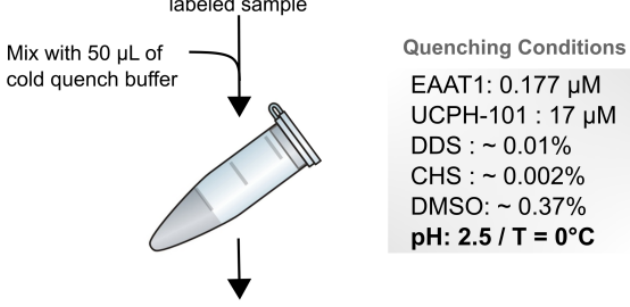

Freeze quenched sample / Store at $-80^{\circ} \mathrm{C}$ 
Fig. 3.

A. Data extraction and analysis

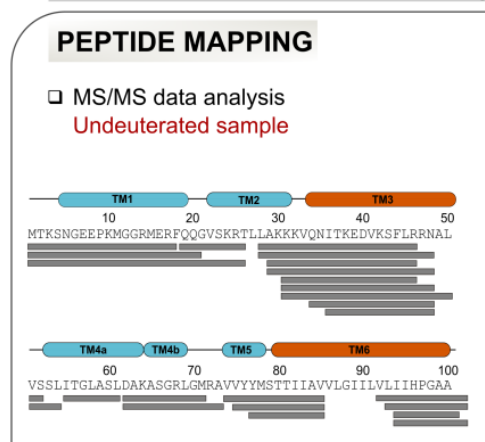

PLGS \& DynamX

C. Local statistical analysis

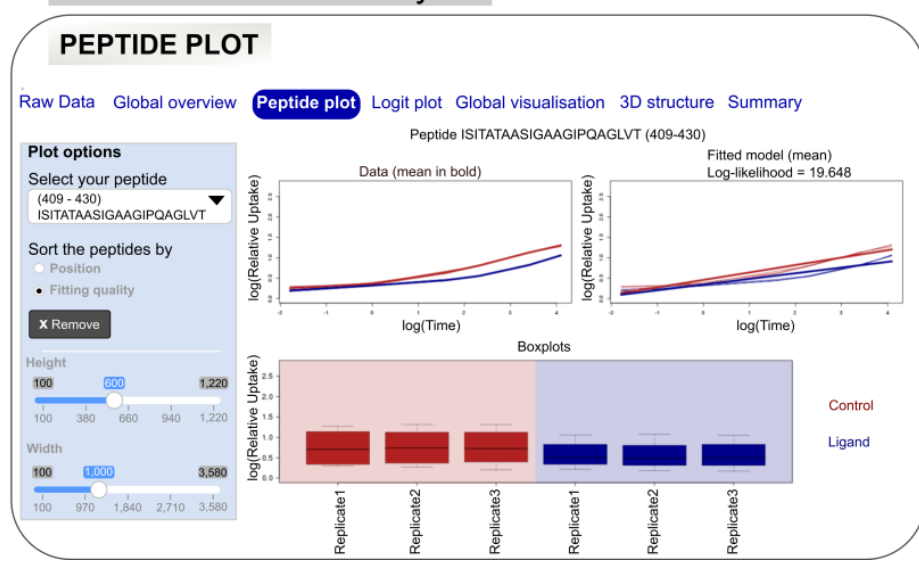

B. Global statistical analysis

\section{DATA EXTRACTION}

- Deuterium Uptake Curves Peptide 1,peptide 2,..., peptide $\mathrm{N}$

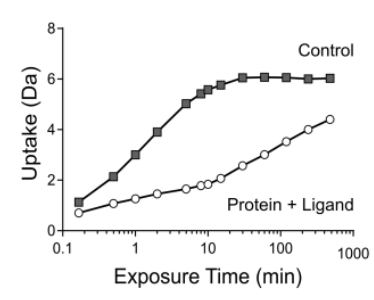

DynamX
BOXPLOTS (Relative Uptake)

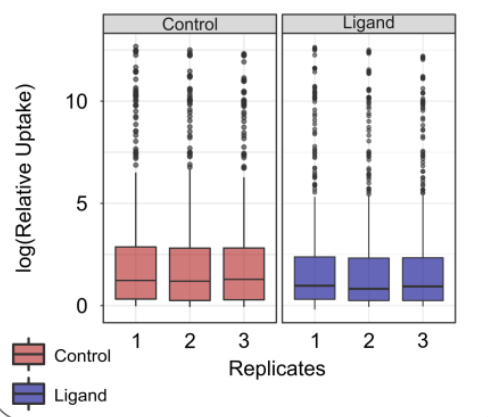

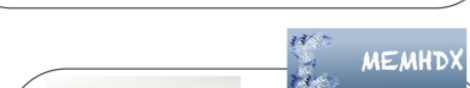

\section{LOGIT PLOT}

Raw Data Global overview Peptide plot Logit plot

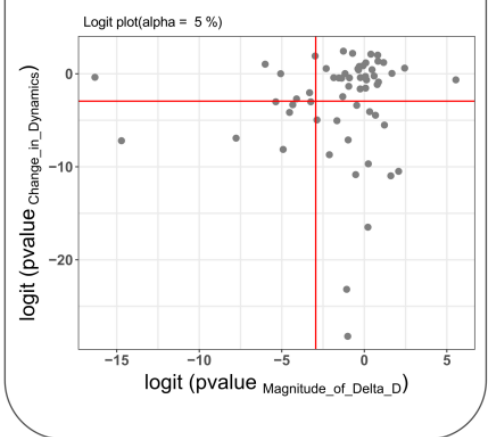


Fig. 4.

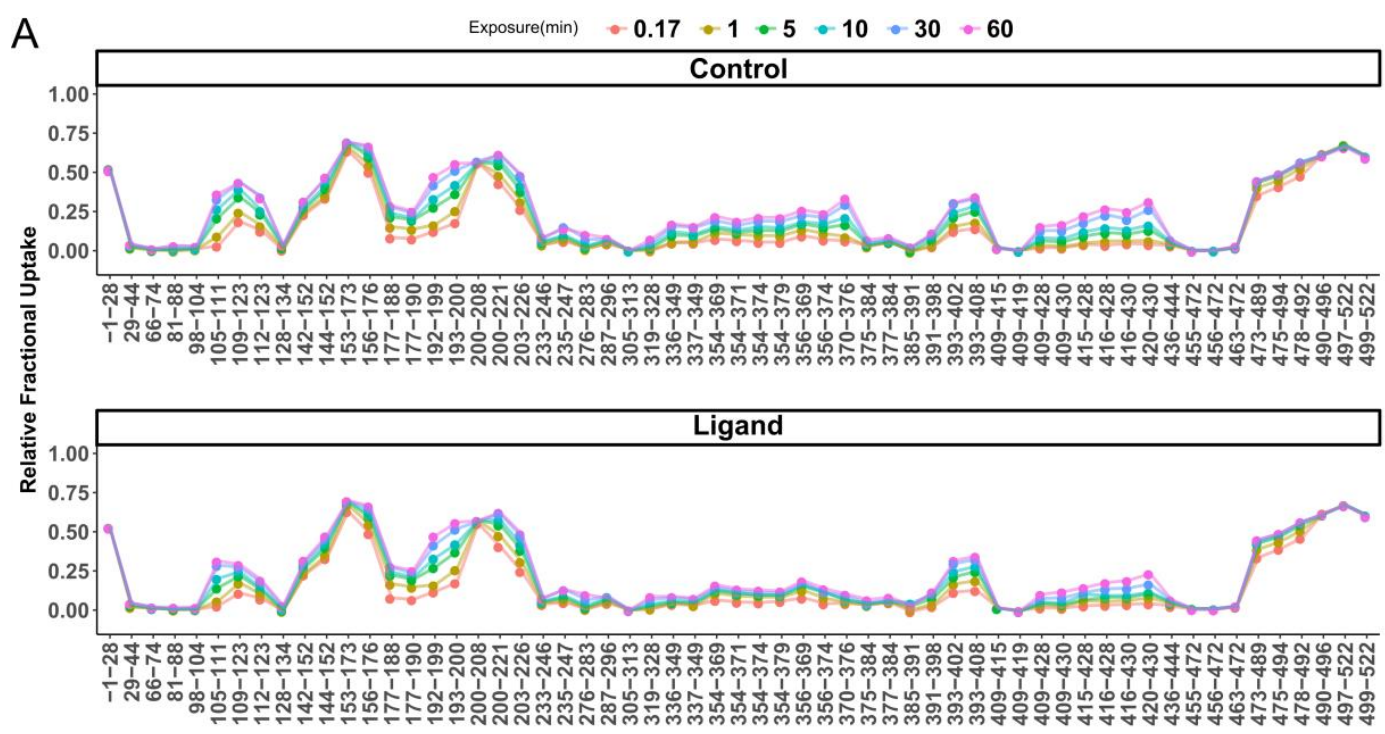

B

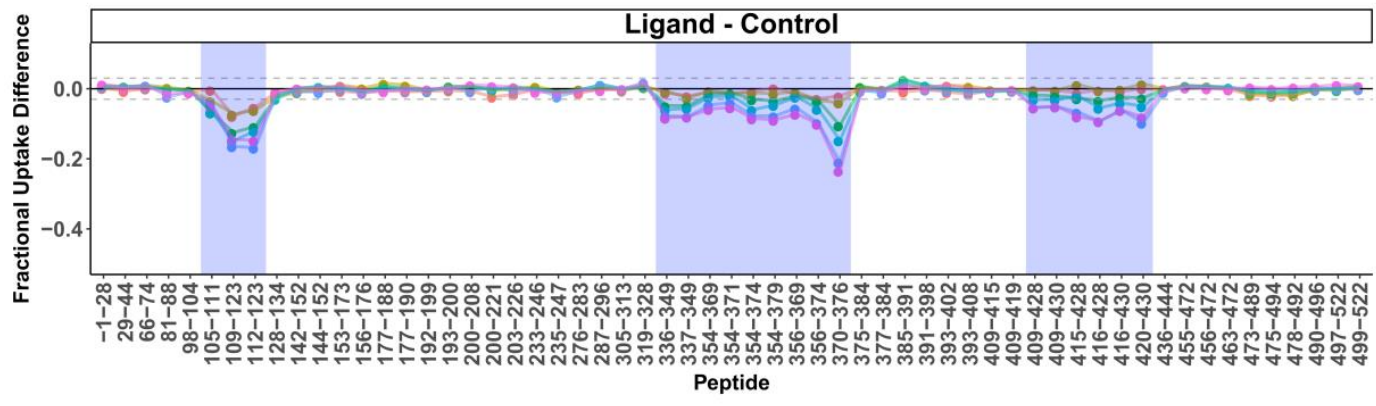

C

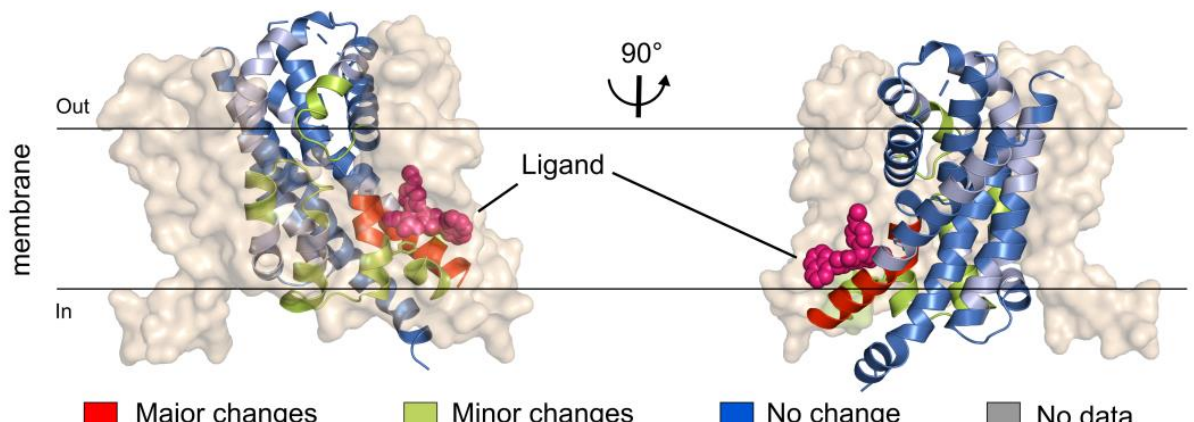


Fig. 5.

(A)

$[$ Complexe $]=\frac{(\text { Kd }+[\text { Protein }]+[\text { ligand }])-\sqrt{(\text { Kd }+[\text { Protein }]+[\text { Ligand }])^{2}-4([\text { Protein }] \cdot[\text { Ligand }])}}{2}$

(B)

$$
\text { Complexe }(\%)=\frac{[\text { Complexe }]}{[\text { Protein }]}
$$

Fig. 5 Equations used to calculate the concentration (a) and percentage (b) of complex during labeling 